\title{
Improvement on Cleaning System of SIROX Tobacco Expander
}

\author{
Guiping $\mathrm{Wu}^{1, *}$, Wei Ding ${ }^{2}$, Mingxing $\mathrm{Li}^{3}$, Kaihua $\mathrm{Yang}^{4}$, Feng $\mathrm{Xie}^{5}$, Qisheng $\mathrm{Chen}^{6}$, and Hanying $\mathrm{Li}^{7}$ \\ ${ }_{1,2,3,4,5,6,7}$ China Tobacco Zhejiang Industrial Co., Ltd. Hangzhou Cigarettes Factory. No. 118, Kehai Road, Hangzhou City, Zhejiang \\ Province, China
}

\begin{abstract}
Based on analyzing SIROX the tobacco expander of its pitfalls on cleaning system like poor drainage, valve leakage, cleaning time consuming, etc., this article proposes an improvement of its cleaning system as well as an optimization of its control mode. Furthermore, this article presents a new design of automatic drainage system of the cleaning pipe as well as a real- time monitoring system. This set of system not only addresses quality issues like the over temperature of cylinder wall of the tobacco dryer and the abnormal fluctuation of the tobacco moisture after dryer, but also visualizes the valve leakage thus helps to improve the prompt maintenance of these devices. Observing the two-year operation in HCF, this system proves a high application value.
\end{abstract}

Warming and humidifying process of tobacco producing process is to warm and humidify the cut leaves and stems to make the temperature and moisture content of the leaves or the stems meet certain requirements, then speedy drying after cylinder drying or air drying, so as to increase the filling value of leaves or stems[1-3]. As a key link of tobacco processing, warming and humidifying process seems extremely significant.

Hangzhou cigarette factory introduced the SIROX tobacco expander produced by German HAUNI company during "the 11th Five-Year" technical transformation, this tobacco expander has the characteristics of large steam flow range, high temperature control and moisture control ability. Because of its good performance and simple operation, it is widely used in various large and medium-sized factories [4]. In the work process, SIROX tobacco expander will use much saturated vapor, while the internal environment of high temperature and humidity leads to serious fouling at the end of the equipment. Due to the high tightness of equipment, artificial cleaning seriously restricts production efficiency. In this paper, the improvement of the cleaning system and the optimization scheme of the control mode are put forward.

\section{Working principle of SIROX}

The SIROX tobacco expander consists of feeding airlock, expansion unit, compressed-air system, vapour system, cleaning system, drainage system and vibration slot [5]. As shown in figure 1, the working principle is as follows: tobacco in the front section flows to rotary rake (1-4) via charging conduit (1-2) and air lock (1-3). The rotary rake shaft is hollow, the hollow pin is screwed in on the shaft, the cylindrical periphery and end face of the pin is provided with a hole of $1.3 \mathrm{~mm}$. Saturated steam is injected through the hollow pin into the tobacco, thereby expanding and humidifying the tobacco. After warming and humidifying, the tobacco falls onto a covered discharging trough (1-6) to enter the next process. While the excess exhaust gas from feed trough and outlet of material vibration trough is exhausted via exhaust fan (17) and exhaust pipe (1-8) [6].

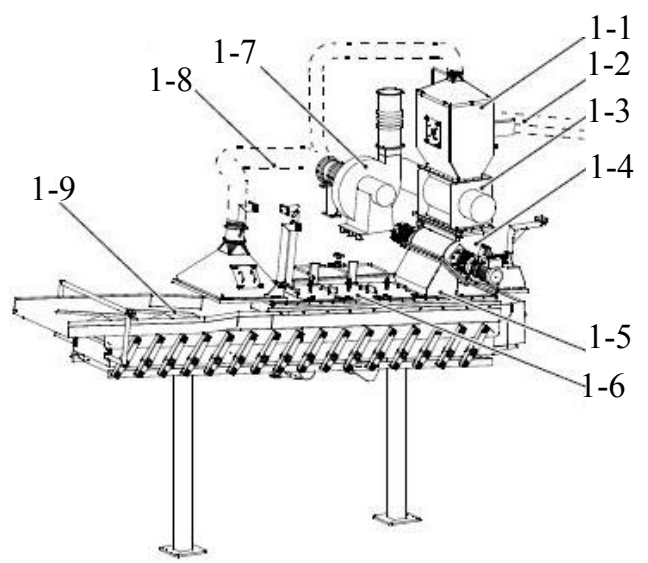

Fig. 1. Structure of SIROX tobacco expander

\section{Problem analysis of SIROX cleaning system}

As shown in figure 2, 5- way clean water is designed on the hydraulic main (2-1) of the SIROX tobacco expander, the role it to clean feed housing (2-2), air lock box (2-3), vibrating tank cover plate (2-4), discharging trough (2-5), and rotary rake (2-6). After automatic cleaning program starts up, each pipeline will clean the key parts in discontinuity based on setup settings, but after running for a period of time, the system has found such problems as poor drainage, leakage from valves and long cleaning time.

Corresponding author: wuguiping@zjtobacco.com 


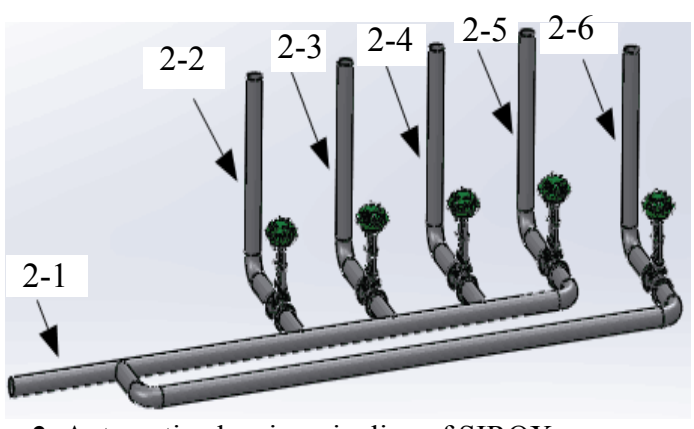

Fig. 2. Automatic cleaning pipeline of SIROX

\subsection{Poor drainage}

Terminal exit of the equipment cleaning pipeline is located above the vibrating slot, with a $2.5 \mathrm{~m}$ drop to pneumatic diaphragm stop valve, each time the automatic cleaning is finished, the valve closes automatically, and a section of water column will be formed on the end of 5-way cleaning pipeline. After the device starts running, the steam flows to the equipment via the shared pipe (2-6) of clean rotary rake to warm and humidify the tobacco. In the production process, water in the remaining 4 road cleaning pipeline will flow to the logistics channel with the vibration of equipment, resulting in the formation of water cured tobacco to affect product quality.

\subsection{Leakage from valve}

Pneumatic diaphragm stop valve is adopted in the cleaning pipeline of the equipment, the spring in the valve seals the spool via guide rod loading fillings. The repeated action of the valve will cause minor wear of the packing and sealing surface and cause water leakage in the stop valve, meanwhile, the pressure difference of 6 bar around the valve will deteriorate the leakage of the valve to a certain extent.

Once valve leakage, the clean water will overflow from the end nozzle to the tobacco production line under the role of pressure difference, which will result in high partial moisture in tobacco, ultra high wall temperature of post process dryer cylinder, abnormal moisture fluctuation after drying, and other problems. As there is no effective means to detect the equipment's valve conditions and leakage degree currently, it will lead to delaying maintenance, and there is a big hidden danger of product quality.

\subsection{Long cleaning time}

According to the technological requirements of our factory, the production and maintenance mode of " 1 time cleaning for every production of 2 batches of tobacco" of SIROX tobacco expander. At present, SIROX automatic cleaning process takes about a total of $20 \mathrm{~min}$, and 2 times of artificial cleaning take about 10 min, each cleaning takes about $30 \mathrm{~min}$. Under current production mode and cleaning frequency, it takes about $1.5 \mathrm{~h}$ per day for SIROX equipment cleaning, which greatly prolongs the batch change time in the production section, seriously affects the continuity of production and reduces the production efficiency.

\section{Improvement measures and effects}

In view of the above 3 problems, transformation and optimization have been made on the SIROX cleaning pipeline, valve control system, automatic cleaning procedures.

\subsection{Improvement on cleaning pipeline}

As shown in Figure 3, one drain pipe line (3-1) is designed on the pneumatic diaphragm stop valve outlet of feed housing, vibrating slot cover plate, discharging trough and rotary rake, the drain pipe line is provided with an air operated ball valve (3-2). And, the pneumatic diaphragm stop valve (3-3) is normally closed, the pneumatic ball valve is normally open, and these two have opposite states of opening and closing: that is, when the pneumatic diaphragm stop valve (3-3) is opened, the new pneumatic ball valve (3-2) is closed; when the pneumatic diaphragm stop valve closes, the pneumatic ball valve opens. The design has the following advantages:

(1)Solve the problem of cleaning water retention in pipe line. When the automatic cleaning program operates, the pneumatic diaphragm stop valve opens and the pneumatic ball valve closes, the clean water cleans the equipment through the original cleaning pipeline; When the automatic cleaning procedure is finished, the pneumatic diaphragm stop valve closes and the pneumatic ball valve opens, the retained water in pneumatic diaphragm stop valve to the end nozzle of clean pipe flows from the new pipe (3-1) under gravity.

(2)Eliminate the hidden trouble on product quality caused from the leakage of pneumatic diaphragm stop valve. If the pneumatic diaphragm stop valve leaks, the leaking water will flow out of the new pipeline and will not overflow the material on the production line, thus eliminating the hidden danger of the product quality.

(3)Realize the visualization inspection of valve leakage. Equipment maintenance personnel can observe whether there is water flow on the production process to determine whether the corresponding pneumatic diaphragm stop valve leaks to conduct timely maintenance after evaluation.

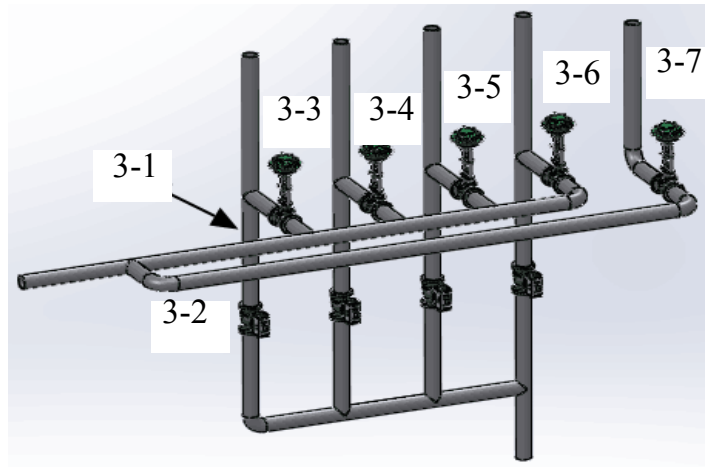

Fig. 3. Improvement on cleaning pipeline 


\subsection{Improvement on valve control system}

The opening and closing of the additional pneumatic ball valve shall be controlled by the pressure air line, while the pressure air valve island of the SIROX does not have enough air pressure modules to be reserved, and after the addition of the module, reprogramming is needed. Therefore, according to the logic relation between the opening and closing of the valve, the existing air pressure pipeline has been reformed in this paper. A 8$\mathrm{mm} \mathrm{T}$ interface is added on the control air pressure pipeline of the pneumatic diaphragm stop valve of above 4 way water pipe, while the pneumatic diaphragm stop valve and pneumatic ball valve on other 2-way pipeline are controlled by by-pass. This added T-interface makes the pneumatic diaphragm stop valve and pneumatic ball valve form an interlocking relationship, a single signal controlled dual actuator is thus implemented: when the corresponding branch valve island module has a signal, the pneumatic diaphragm stop valve opens and the pneumatic ball valve closes; When the module has no signal, the pneumatic diaphragm stop valve closes and the pneumatic ball valve opens.

\subsection{Optimization on automatic cleaning program}

SIROX automatic cleaning process carries out 5 cycles, each cycle is divided into 8 stages, the 5 -way cleaning pipeline in each stage cleans the corresponding parts according to procedures.

After repeated tests by the project team, the opening of each valve has been determined, as shown in table 1 .

Table 1. Cleaning valve opening at all stages in automatic cleaning process

\begin{tabular}{|c|c|c|c|c|c|}
\hline stage & $\begin{array}{c}\text { valve } \\
\mathbf{2 - 4} \\
\mathbf{( 3 - 5 )}\end{array}$ & $\begin{array}{c}\text { valve } \\
\mathbf{2 - 5} \\
\mathbf{( 3 - 6 )}\end{array}$ & $\begin{array}{c}\text { valve } \\
\mathbf{2 - 3} \\
\mathbf{( 3 - 4 )}\end{array}$ & $\begin{array}{c}\text { valve } \\
\mathbf{2 - 2} \\
\mathbf{( 3 - 3 )}\end{array}$ & $\begin{array}{c}\text { valve } \\
\mathbf{2 - 6} \\
\mathbf{( 3 - 7 )}\end{array}$ \\
\hline Stage 1 & Off & On & On & On & On \\
\hline Stage 2 & Off & On & On & On & Off \\
\hline Stage 3 & Off & On & On & On & On \\
\hline Stage 4 & On & Off & Off & On & Off \\
\hline Stage 5 & On & Off & Off & On & On \\
\hline Stage 6 & On & Off & Off & On & Off \\
\hline Stage 7 & On & Off & Off & On & On \\
\hline Stage 8 & On & Off & Off & On & On \\
\hline
\end{tabular}

After completing the program improvement, the project team will evaluate the cleaning effectiveness. The team has carried out 4 cleaning effect evaluation successively, the evaluation results are consistent. Table 2 shows the fourth evaluation record.

Table 2. Cleaning effect evaluation in each cleaning stage of SIORX

\begin{tabular}{|c|c|c|c|c|c|}
\hline $\begin{array}{c}\text { Cleaning } \\
\text { stages }\end{array}$ & $\begin{array}{c}\text { One } \\
\text { cycle }\end{array}$ & $\begin{array}{c}\text { Two } \\
\text { cycles }\end{array}$ & $\begin{array}{c}\text { Three } \\
\text { cycles }\end{array}$ & $\begin{array}{c}\text { Four } \\
\text { cycles }\end{array}$ & $\begin{array}{c}\text { Five } \\
\text { cycles }\end{array}$ \\
\hline
\end{tabular}

\begin{tabular}{|c|c|c|c|c|c|}
\hline $\begin{array}{c}\text { Feed } \\
\text { housing }\end{array}$ & $\begin{array}{c}\text { Not } \\
\text { clean }\end{array}$ & $\begin{array}{c}\text { Not } \\
\text { clean }\end{array}$ & Clean & Clean & Clean \\
\hline Airlock box & $\begin{array}{c}\text { Not } \\
\text { clean }\end{array}$ & $\begin{array}{c}\text { Not } \\
\text { clean }\end{array}$ & Clean & Clean & Clean \\
\hline Rotary rake & $\begin{array}{c}\text { Not } \\
\text { clean }\end{array}$ & Clean & Clean & Clean & Clean \\
\hline $\begin{array}{c}\text { Vibrating } \\
\text { tank cover } \\
\text { plate }\end{array}$ & $\begin{array}{c}\text { Not } \\
\text { clean }\end{array}$ & $\begin{array}{c}\text { Not } \\
\text { clean }\end{array}$ & Clean & Clean & Clean \\
\hline $\begin{array}{c}\text { Discharging } \\
\text { trough }\end{array}$ & $\begin{array}{c}\text { Not } \\
\text { clean }\end{array}$ & $\begin{array}{c}\text { Not } \\
\text { clean }\end{array}$ & Clean & Clean & Clean \\
\hline
\end{tabular}

Based on the 4 cleaning effect evaluation, the optimized SIROX tobacco expander has reached the goal of thoroughly cleaning the key parts after the third cleaning cycle.

\section{SUMMARY}

In this paper, the problem of poor drainage is solved by the retained clean water in linkage relation evacuation line of pneumatic ball valve and pneumatic diaphragm stop valve; and the hinder danger of flowing into the production line due to leakage of pneumatic diaphragm stop valve is eliminated by the normally opening drain pipeline, which guarantees product quality. And, the leakage condition of the pneumatic diaphragm stop valve is quantified by observing the effluent situation of the emptying pipeline, which improves the timeliness of equipment maintenance. Meanwhile, by optimizing the cleaning process and the number of cycles, the cleaning time is reduced, and the water resource is saved, and the stability of the SIROX tobacco expander and the efficiency of the production are further enhanced. Therefore, the project has achieved remarkable results in the application of Hangzhou cigarette factory, which has high application value.

\section{References}

1. Chen-zhe Song, Guang-zhou Liu, Zhe Jin, etc. Study on tobacco expansion effect using steam expansion technology. Journal of Zhengzhou University of Light Industry (Natural Science Edition), 12,29(2014).

2. Zhi-yan Chen. Effects on the Characteristics of Cut Stems of Flue-cured Tobacco in the Process of the Expansion Drying. Journal Of Anhui Agricultural Sciences, 38, 7262-7263( 2010).

3. Yong-ren Zhang, Zhe-kun Li, Yan-hong Song, etc. The Research of SIROX Warming and Humidification Equipment. New Technology \& New Process, 10, 6-8(2015).

4. Quan-dao Wang, Optimization of technological parameters of tunnel-type expanded processing of cut stem, Acta Agriculturae Jiangxi, 23, 100103(2011). 
5. Liang Zhou, China tobacco commercial enterprise development direction. Journal of hunan university of arts and sciences(natural science edition), 6, 9294(2011).

6. Zhi-hui He, Jia Luo, Wen-liu Lian, etc. The Fourier transform of cigarette tar is near infrared measurement technology. Journal of hunan university of arts and sciences(natural science edition), 9, 59-67(2009). 